Supporting Information

\title{
Graphene-Silver-Induced Self-Polarized PVDF-Based Flexible Plasmonic Nanogenerator Toward the Realization for New Class of Self Powered Optical Sensor
}

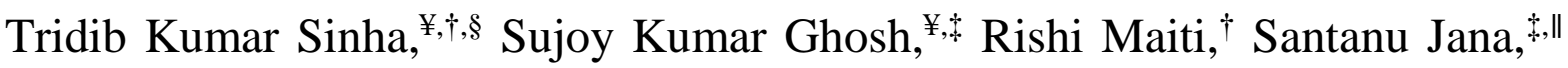
Basudam Adhikari, ${ }^{\S}$ Dipankar Mandal, ${ }^{* \neq}$ and Samit K. Ray ${ }^{*} \dagger$

†Department of Physics and ${ }^{\S}$ Material Science Centre, Indian Institute of Technology, Kharagpur 721302, India

E-mail: physkr@phy.iitkgp.ernet.in

Organic Nano-Piezoelectric Device Laboratory, Department of Physics, Jadavpur University, Kolkata 700032, India

E-mail: dipankar@phys.jdvu.ac.in

" Department of Electronics, Netaji Nagar Day College, 170/436 N. S. C Bose Road, Kolkata 700092, India

${ }^{¥}$ T.K.S. and S.K.G. contributed equally to this work. 


\section{Experimental Section:}

\section{Synthesis of graphene from graphite}

In this typical procedure, graphite $(1 \mathrm{~g})$ powder (Sigma-Aldrich) was exfoliated in saturated brine solution $(25 \mathrm{~mL})$ by ultrasonication for $30 \mathrm{~m}$. A black homogenous dispersion appeared with precipitates of unexfoliated graphite. Afterwords, $25 \mathrm{~mL}$ of ethyl acetate (EtOAc) was added to the homogenous dispersion and the whole mixture was further ultrasonicated for 10 m. A glazy blackish mass appeared in between the organic-aqueous interfaces. The black mass was extracted by the removal of brine solution followed by washing the organic part (that carrying the blackish mass) with plenty of water for several times. Then it was dried by nitrogen $\left(\mathrm{N}_{2}\right)$ bubbling (to avoid restacking) and dispersed in N-Methyl 2-Pyrrolidone (NMP) under the ultrasonication. Finally, a greyish black NMP dispersion of graphene is prepared.

\section{Film preparation}

To make the PVDF/graphene/Ag composite solution, first $5 \mathrm{wt} \%(\mathrm{mg} / 100 \mathrm{~mL})$ silver nitrate salt was added with the greyish black NMP-dispersion of graphene $(5 \mathrm{mg} / \mathrm{mL})$ and sonicated for $20 \mathrm{~m}$, solution colour changes to blackish orrange. Then $6 \mathrm{wt} \%$ (w/v) of PVDF (SigmaAldrich, USA, $\mathrm{M}_{\mathrm{w}}=275$ 000) were mixed followed by stirring for 7 days at room temperature. The free standing flexible film with $80 \mu \mathrm{m}$ of thickness was prepared by solution casting technique using the aforementioned prepared solution followed by vacuum drying at $120^{\circ} \mathrm{C}$ for $8 \mathrm{~h}$. The film was designated as PVGAg. A reference sample, designated as NPV film was also prepared under same condition using a pure PVDF-NMP solution without any external additives.

\section{PNG fabrication}

To fabricate the PNG a thin layer $(\sim 30 \mathrm{~nm})$ of gold $(\mathrm{Au})$ electrodes on both sides of PVGAg film were deposited by a magnetron sputtering coater over shadow mask of area $1.22 \mathrm{~cm}^{2}$ at the deposition rate of $0.13 \mathrm{~nm} . \mathrm{s}^{-1}, 0.1 \mathrm{mTorr}$ of the working pressure, $2.5 \mathrm{kV}$ of the applying 
voltage, $20 \mathrm{~mA}$ of current and at the target to specimen distance of $50 \mathrm{~mm}$. The electrical output leads were connected on either side of the film.
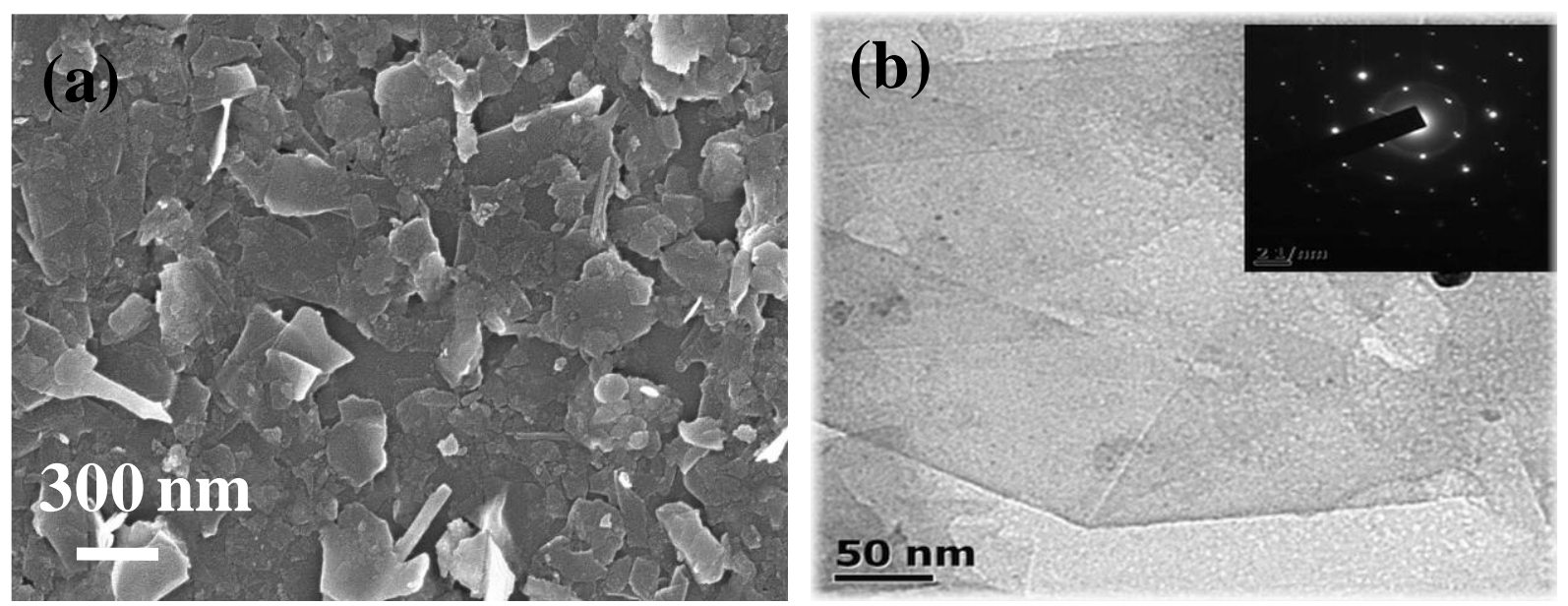

Figure S1. (a) FESEM image (b) HRTEM micrograph with SAED pattern (inset) of few layer graphene (FLG) prepared by direct exfoliation of graphite. Flake size is ranging from $50 \mathrm{~nm}$ to $1000 \mathrm{~nm}$

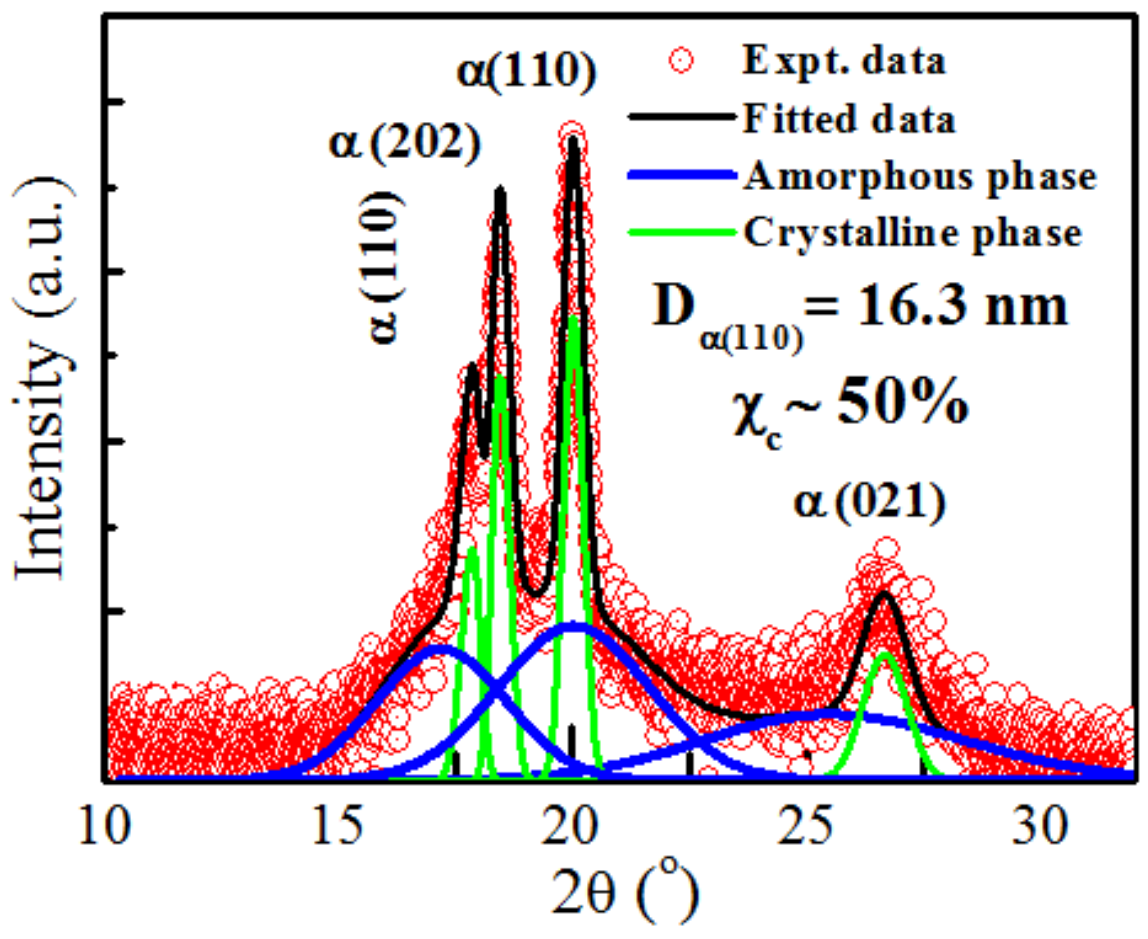

Figure S2. The XRD pattern of the NPV film in the range of $2 \theta=10-32^{\circ}$. The degree of crystallinity $\left(\chi_{c}\right)$ in the PVGAg and NPV film (listed in table S1) is calculated by, $\chi_{c}=$ 
$\frac{\sum A_{c r}}{\sum A_{c r}+\sum A_{a m r}} \times 100 \%$ where $\sum A_{c r}$ and $\sum A_{a m r}$ are the summation of integral area of crystalline peaks and amorphous halo respectively. The crystallite size of $\alpha\left(D_{\alpha}\right)$ (depicted in inset of the figure), $\beta\left(D_{\beta}\right)$ and $\gamma\left(D_{\gamma}\right)$ crystals are calculated from Debye-Scherrer equation, $D=\frac{k \lambda}{\beta \cos \theta}$, where $k$ is a constant $(0.89)$ and $\lambda$ is the wavelength $(0.154178 \mathrm{~nm})$ of the X-ray radiation, $\beta$ is the full-width (in radian) at half-maximum (FWHM) of the principal diffraction peak and $\theta$ is the angle of diffraction.

Table S1

\begin{tabular}{lccc}
\hline $\begin{array}{l}\text { Name of the } \\
\text { Samples }\end{array}$ & $\frac{\sum \boldsymbol{A}_{\boldsymbol{c} r}}{\sum \boldsymbol{A}_{\boldsymbol{a m r} r}}$ & $\chi_{\boldsymbol{c}}=\frac{\sum \boldsymbol{A}_{\boldsymbol{c} r}}{\sum \boldsymbol{A}_{\boldsymbol{c} r}+\sum \boldsymbol{A}_{\boldsymbol{a m r}}} \times \mathbf{1 0 0} \%$ & $\chi_{\boldsymbol{\beta}}(\%)=\boldsymbol{F}(\boldsymbol{\beta}) \times \chi_{\boldsymbol{c}}(\%)$ \\
\hline NPV film & 1.0 & $50 \%$ & - \\
$\begin{array}{l}\text { PVGAg } \\
\text { film }\end{array}$ & 0.67 & $40 \%$ & $26 \%$ \\
\hline
\end{tabular}

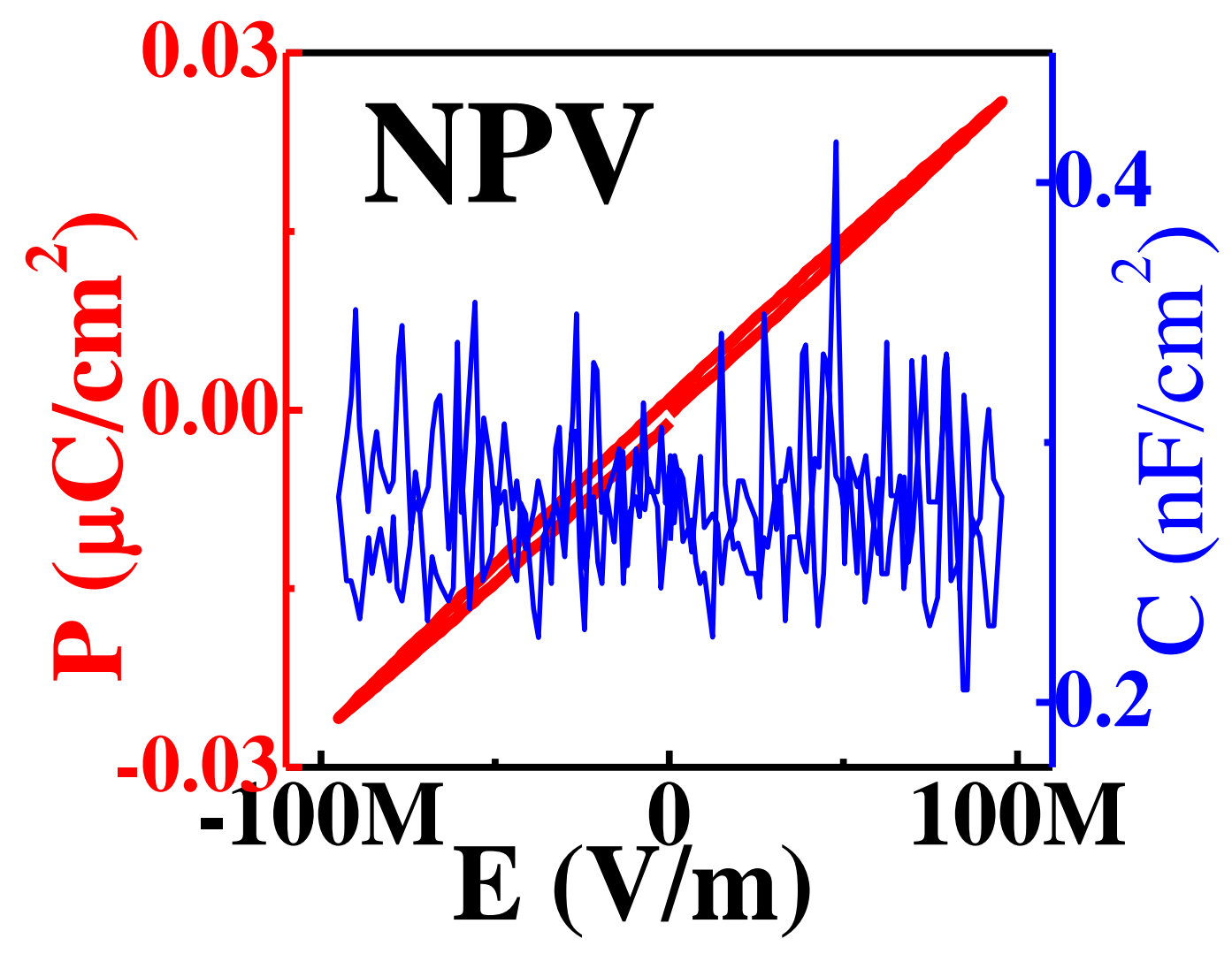


Figure S3. The P-E (red colour) loop and C-E (blue colour) characteristic of the NPV film in the range of electric field, $\mathrm{E} \sim \pm 100 \mathrm{MV} / \mathrm{m}$.

(a)

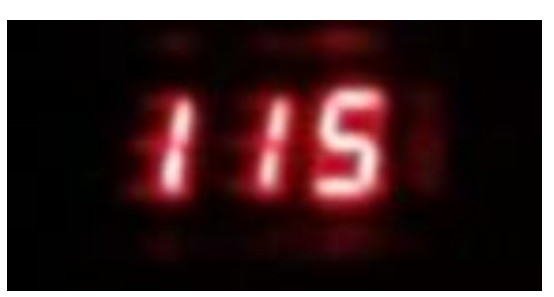

(b)

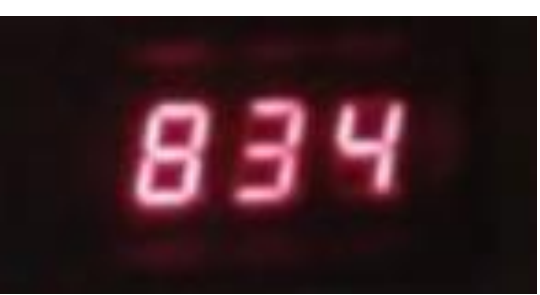

Figure S4. The display of maximum output short circuit current $\left(\mathrm{I}_{\mathrm{sc}}\right)$ from PNG under 5.2 $\mathrm{kPa}$ of stress amplitude.(a) In dark condition, $\mathrm{I}_{\mathrm{sc}} \approx 115 \mathrm{pA}$ and (b) under the illumination of light, $\mathrm{I}_{\mathrm{sc}} \approx 834 \mathrm{pA}$.

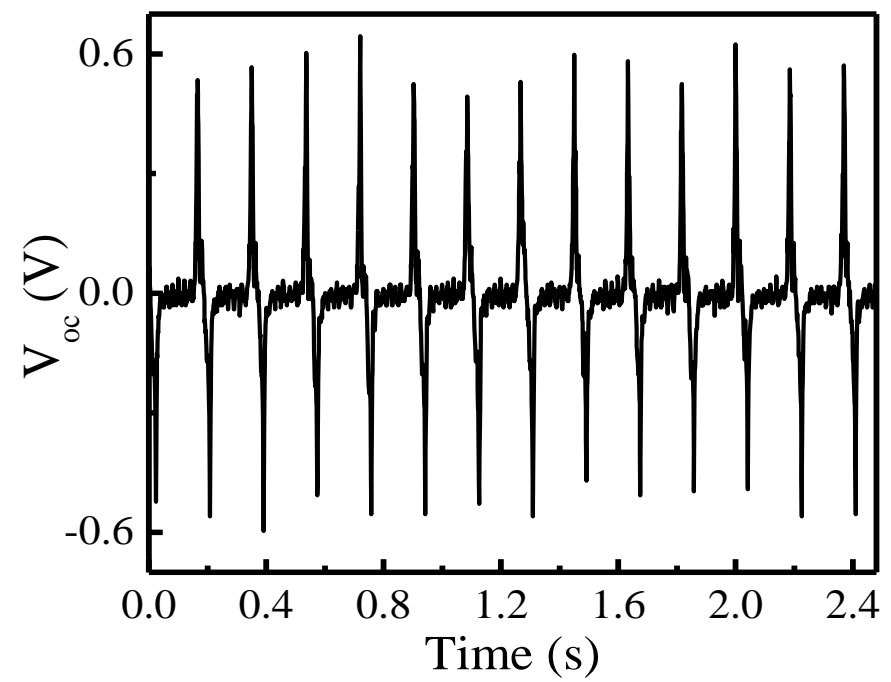

Figure S5. The output open circuit voltage $\left(\mathrm{V}_{\mathrm{oc}} \sim 600 \mathrm{mV}\right)$ of PNG under the $\sigma_{\mathrm{a}} \sim 10 \mathrm{kPa}$ in dark condition. 


\section{Associate discussion S1. Calculation of applied stress amplitude:}

The calculation of the contact pressure induced by falling object (here, pressure imparting probe) was based on the physical model combining the gravity term and the pulse term. ${ }^{[\mathrm{S} 1, \mathrm{~S} 2, \mathrm{~S} 3]}$ When the object falls on the PNG, there exist two processes: 1) initially touching the surface, and 2) completely acting on the PNG. The descending velocity of the object increases to maximum in the first process and decreases to zero in the second one. Therefore, based on the classical kinetic energy and momentum theorem, we have

$m \cdot g \cdot h=\frac{1}{2} \cdot m \cdot v^{2}$

$(F-m g) \cdot \Delta t=m \cdot v$

$\sigma_{a}=\frac{F}{S}$

where $m=0.05 \mathrm{~kg}$ is the mass of the imparting probe, $h=3 \mathrm{~cm}$ is the distance between the probe and PNG, $v$ is the maximum falling velocity, $\sigma_{a}=5.2 \mathrm{kPa}$ is the axial stress, $F=0.64$ Nis the axial force, $S=1.22 \mathrm{~cm}^{2}$ is the contact area, and $\Delta t$ is the time span during second process and estimated from the time variation between two voltage peaks, $g=9.8 \mathrm{~N} / \mathrm{kg}$ and $m$ was determined by the laboratory balance.

\section{Associate discussion S2.}

To perform the finite element method (FEM) simulation model a geometrical configuration was considered where fixed constrained is the lower electrode and the bottom of the PNG was electrically grounded (Figure R6). To simplify the simulation, an external boundary load i.e., stress $(\sim 5.2 \mathrm{kPa})$ was applied to the upper electrode and other boundaries of the PNG were considered as symmetric. 


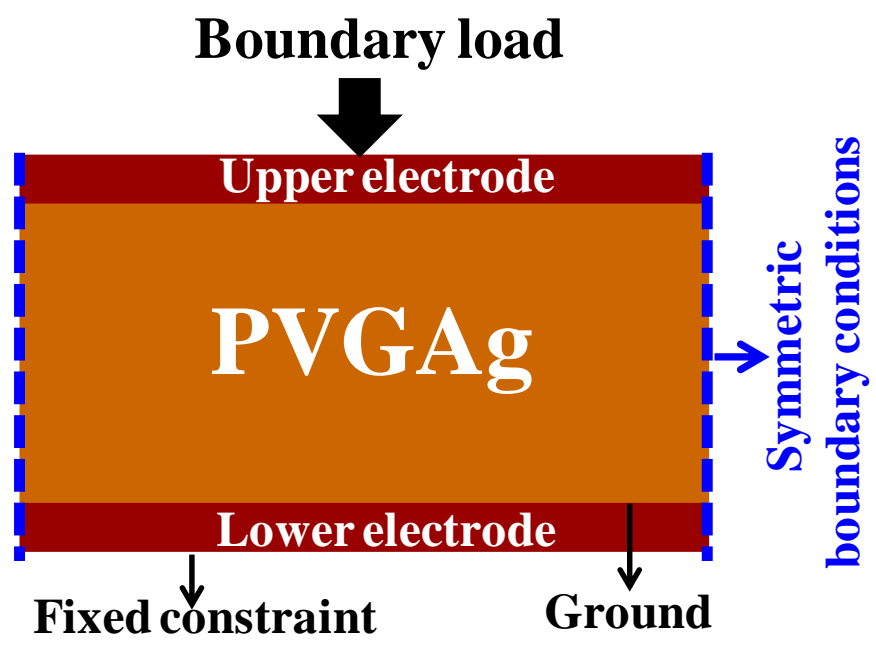

Figure S6. The geometrical configuration of the FEM simulation model.

\begin{tabular}{llll}
\hline Property & Variable & Expression & Unit \\
& & & \\
\hline Elasticity matrix & $\mathrm{C}_{\mathrm{E}}$ & $\left\{\left\{1.5 \times 10^{9}, 5.21 \times 10^{9}, 4.78 \times 10^{9}, 0,0,0\right\}\right.$, & $\mathrm{Pa}$ \\
& $\left\{5.21 \times 10^{9}, 2.36 \times 10^{9}, 5.21 \times 10^{9}, 0,0,0\right\}$, \\
& $\left\{4.78 \times 10^{9}, 5.21 \times 10^{9}, 2.12 \times 10^{9}, 0,0,0\right\}$, \\
& $\left\{0,0,0,1.5 \times 10^{9}, 0,0\right\}$, \\
& \\
& $\left\{0,0,0,0,1.5 \times 10^{9}, 0\right\}$, \\
& & \\
& $\left.\left\{0,0,0,0,0,1.5 \times 10^{9}\right\}\right\}$
\end{tabular}




\begin{tabular}{llll}
\hline Coupling matrix & $\mathrm{e}$ & $\{\{0,0,-4.761,0,0,-33.33\}$, & $\mathrm{C} / \mathrm{m}^{2}$ \\
& & $\{0,0,3.703,0,1.703,0\}$, & \\
& & $\{1.703,0,0,0,0,0\}\}$ & \\
Compliance matrix & $\mathrm{S}_{\mathrm{E}}$ & $\left\{6.67 \times 10^{-10}, 6.67 \times 10^{-10}, 6.67 \times 10^{-10}, 0,0, \mathrm{~Pa}^{-1}\right.$ \\
& & $0\}$ & 1 \\
Relative & & $\{\{38,0,0\},\{0,38,0\},\{0,0,38\}\}$ & $\mathrm{kg} / \mathrm{m}^{3}$ \\
permittivity & $\varepsilon_{\mathrm{r}}$ & & \\
Density & & 1780 & \\
Poisson's ratio & $v$ & 0.34
\end{tabular}

The piezopotential distribution inside PNG during applied stress $(\sim 5.2 \mathrm{kPa})$ has been calculated via FEM simulation using COMSOL Multiphysics software. To conduct the simulations the following values have been employed, such as, Young's modulus, $\mathrm{Y} \sim 1.5 \mathrm{GPa}$, piezoelectric charge constant, $\mathrm{d}_{33}=-1.32 \mathrm{pC} / \mathrm{N}$, converse piezoelectric coefficient, $\mathrm{g}_{33}=-3.92 \times 10^{-3} \mathrm{Vm} / \mathrm{N}$ and electromechanical coupling factor $(\mathrm{k})$ which is determined from the equation, $k^{2}=Y \times g_{i j} \times d_{i j}=Y \times \frac{d_{i j}^{2}}{\varepsilon^{T}}$ where, $\varepsilon^{T}$ is the dielectric permittivity of PVGAg. Some values which are required to conduct the simulation is obtained from reference S4 and listed in Table R1.

We solved the following linear mechanical equation 1 that links the stress $\mathrm{T}$ to the applied force $\mathrm{F}$ on the PNG and the Poisson equation 2 that links the electric displacement $\mathrm{D}$ to the fixed charge density $\rho_{\mathrm{V}}$,

$-\nabla . \mathrm{T}=\mathrm{F}$ 


$$
\nabla \cdot \mathrm{D}=\rho_{\mathrm{V}}
$$

The coupling between the structural and electrical domains can be expressed in the form of a connection between the material stress and its permittivity at constant stress or as a coupling between the material strain and its permittivity at constant strain. The equations $(1,2)$ are coupled to the piezoelectric equations of strain-charge form $(3,4)$ and stress-charge form $(5,6)$ that correlate the stress $\mathrm{T}$ tensor, strain $\mathrm{S}$, electric displacement $\mathrm{D}$ and the electric field E using the permittivity $\varepsilon$, elasticity tensor $\mathrm{c}$ and piezoelectric coupling tensor e and $\mathrm{d}$.

Strain-Charge form:

The strain-charge form of a piezoelectric material is written as,

$$
\begin{aligned}
& S=s_{E} \cdot T+d^{T} \cdot E \ldots \\
& D=d \cdot T+\varepsilon_{0} \cdot \varepsilon_{r T} E
\end{aligned}
$$

The material parameters $\mathrm{s}_{\mathrm{E}}, \mathrm{d}$, and $\varepsilon_{\mathrm{rT}}$ correspond to the material compliance, coupling properties, and relative permittivity at constant stress. $\varepsilon_{0}$ is the permittivity of free space.

Stress-Charge form:

The stress-charge form of the piezoelectric material is written as,

$$
\begin{aligned}
& \mathrm{T}=\mathrm{c}_{\mathrm{E}} \cdot \mathrm{S}+\mathrm{e}^{\mathrm{T}} \cdot \mathrm{E} \ldots \ldots \\
& \mathrm{D}=\mathrm{e} \cdot \mathrm{S}+\varepsilon_{0} \cdot \varepsilon_{\mathrm{rS}} \cdot \mathrm{E}
\end{aligned}
$$

The material parameters $\mathrm{c}_{\mathrm{E}}, \mathrm{e}$, and $\varepsilon_{\mathrm{rS}}$ correspond to the material stiffness, coupling properties, and relative permittivity at constant strain.

\section{Associate discussion S3.Overall efficiency of PNG:}

During capacitor charging, the axial stress $\sigma_{a}=5.2 \mathrm{kPa}$ was applied to PNG. The axial deformation of the device under $5.2 \mathrm{kPa}$ of stress is $\Delta L=\varepsilon \times L$ where, $\varepsilon$ is axial strain and $\mathrm{L}$ is the thickness. The axial strain is calculated by, $\varepsilon=\frac{\sigma_{a}}{Y}=3.47 \times 10^{-6}$ where $\sigma_{a}=5.2 \mathrm{kPa}$ 
is the axial stress and $Y=1.5 \mathrm{GPa}$ is the Young's modulus (Supporting information, Figure S7). In capacitor charging process, the input mechanical energy per cycle is becoming, $F \times$ $\Delta L=1.78 \times 10^{-10} \mathrm{~J}$. The total energy harvested by PNG and subsequently stored in the capacitor depends on the total number of cycle $\left(n_{c y}\right)$ required to completely charge up the capacitor. The total mechanical input energy required to reach the capacitor charging voltage to its saturation voltage $\left(\mathrm{V}_{\mathrm{s}}\right)$ is, $W_{\text {in }}=F \times \Delta L \times n_{c y}$. The overall efficiency of the PNG can now be written as, $\eta_{\text {piezo }}=\frac{W_{\text {out }}}{W_{\text {in }}} \times 100 \%$.

Table S2

\begin{tabular}{|c|c|c|c|c|c|c|c|}
\hline & $C(\mu F)$ & $\mathbf{V}_{\mathrm{s}}(\mathrm{V})$ & $\mathbf{W}_{\text {out }}(\mathbf{J})$ & $t$ (sec) & $n_{c y}$ (number) & $\mathbf{W}_{\text {in }}(\mathbf{J})$ & $\eta_{\text {piezo }}(\%)$ \\
\hline $\begin{array}{c}\text { Dark } \\
\text { condition }\end{array}$ & 1 & 0.097 & $4.7 \times 10^{-9}$ & 35 & 175 & $3.11 \times 10^{-8}$ & 15 \\
\hline Red light & 1 & 0.097 & $4.7 \times 10^{-9}$ & 35 & 175 & $3.11 \times 10^{-8}$ & 15 \\
\hline Blue light & 1 & 0.12 & $7.3 \times 10^{-9}$ & 45 & 225 & $4.00 \times 10^{-8}$ & 18.3 \\
\hline White & 1 & 0.17 & $13.9 \times 10^{-9}$ & 49 & 245 & $4.36 \times 10^{-8}$ & 31.9 \\
\hline \multicolumn{8}{|l|}{ light } \\
\hline Green & 1 & 0.17 & $14.5 \times 10^{-9}$ & 35 & 175 & $3.11 \times 10^{-8}$ & 46.6 \\
\hline light & & & & & & & \\
\hline
\end{tabular}




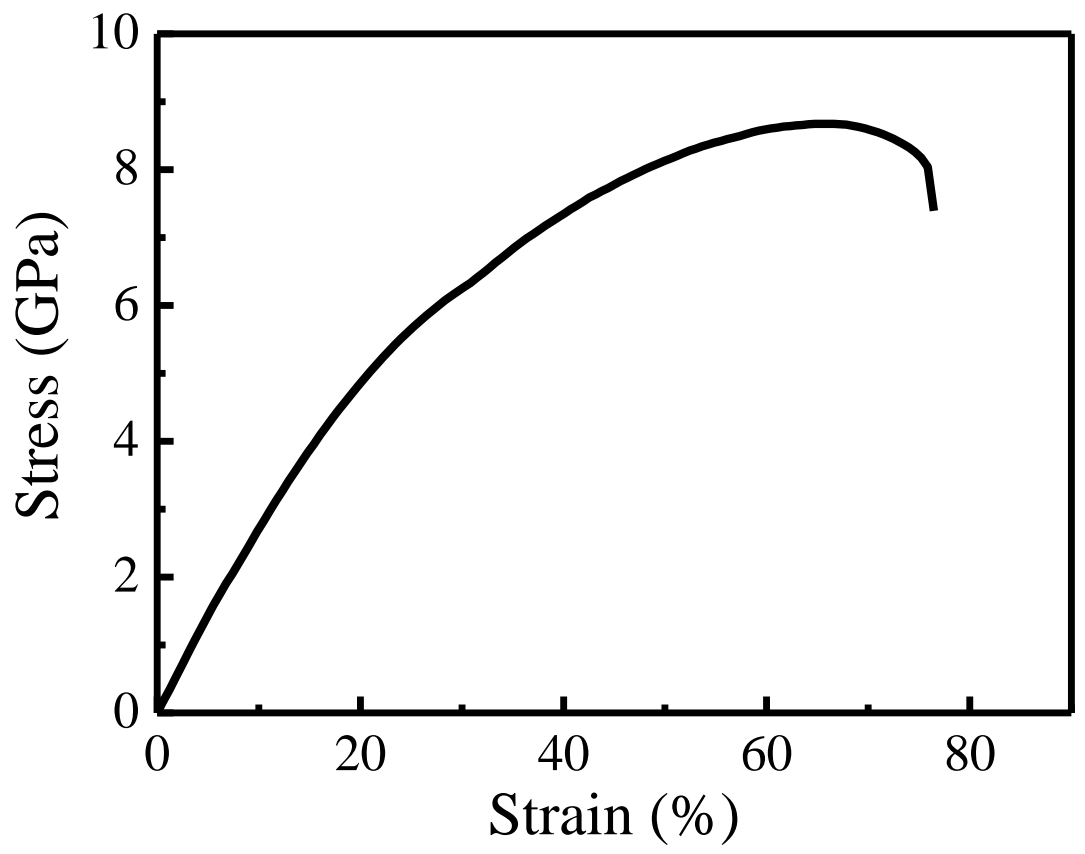

Figure S7. The stress-strain curve evaluates the Young's modulus of the PVGAg film (25 (length) $\times 10 \mathrm{~mm}$ (width) $\times 0.008 \mathrm{~mm}$ (thickness) ) as $1.5 \mathrm{GPa}$ following the procedure ASTM D638 using an electromechanical universal testing machine (Shimadzu).

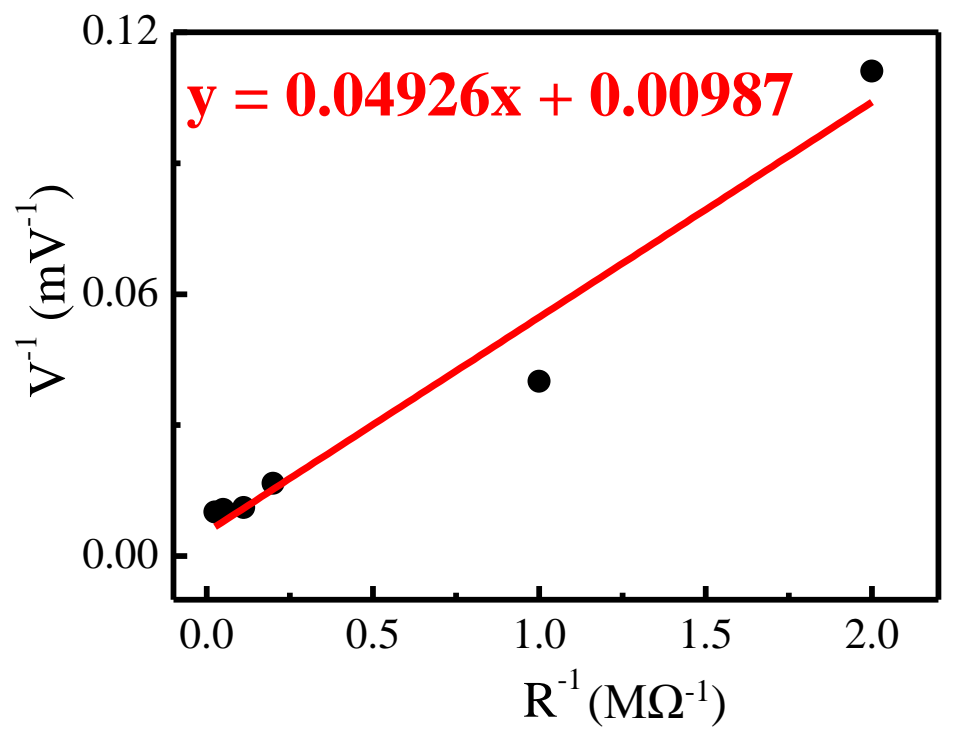

Figure S8. Calculation of the open circuit voltage and internal resistance of PNGusing the data shown in Figure $3 d$. The linear fit of the data from Figure $3 d$ is exactly the result of 
linear circuit theory that uses the PNG as a power source with a fixed output voltage of 101 $\mathrm{mV}$.

Associate discussion S4: As we have observed when gradually changing the amount of load resistance (from 0.1 to $40 \mathrm{M} \Omega$ ), the magnitude of the voltage drop across the resistor changes accordingly. The voltage on the resistor is $V=\frac{V_{0} R}{R+r}$, where $V_{o}$ is the open circuit voltage from the PNG, $\mathrm{r}$ is its internal resistance, and $\mathrm{R}$ is the resistance of the load resistor.

Thus, $\frac{1}{\mathrm{~V}}=\frac{\mathrm{r}}{\mathrm{V}_{0}} \cdot \frac{1}{\mathrm{R}}+\frac{1}{\mathrm{~V}_{0}}$ from the plot of $\frac{1}{V}$ vs. $\frac{1}{R}$ shown in the Figure S6. We have found that open circuit voltage $\left(\mathrm{V}_{0}\right)$ is $101 \mathrm{mV}$ which is the close agreement with our experimental observation (Figure 3a). Thus, in the indoor (i.e., dark condition), the internal resistance of the PNG is 4.97 M $\Omega$. Using the same pathway the internal resistance of the PNG in the presence of external light source is $2.46 \mathrm{M} \Omega$, considering the open circuit voltage, $V_{0}=50$ $\mathrm{mV}$ which is observed experimentally (Figure 4a).

\section{REFERENCES}

S1. Hou, C.; Huang, T.; Wang, H.; Yu, H.; Zhang, Q.; Li, Y. A Strong and Stretchable SelfHealing Film with Self-Activated Pressure Sensitivity for Potential Artificial Skin Applications. Sci. Rep. 2013, 3, 3138.

S2. Alam, M. M.; Ghosh, S. K.; Sultana, A.; Mandal, D. Lead-Free $\mathrm{ZnSnO}_{3} / \mathrm{MWCNTs}^{-}$ Based Self-Poled Flexible Hybrid Nanogenerator for Piezoelectric Power Generation. Nanotechnology 2015, 26 (16), 165403(6pp).

S3. Fan, F.-R.; Li, L.; Zhu, G.; Wu, W.; Zhang, R.; Wang, Z. L. Transparent Triboelectric Nanogenerators and Self-Powered Pressure Sensors Based on Micropatterned Plastic Films

Nano Lett. 2012, 12, 3109-3114. 
S4. Silva, M.; Reis, S.; Lehmann, C. S.; Martins, P.; Lanceros-Mendez, S.; Lasheras, A.; Gutiérrez, J.; Barandiarán, J. M. Optimization of the Magnetoelectric Response of Poly(vinylidene fluoride)/Epoxy/Vitrovac Laminates. ACS Appl. Mater. Interfaces 2013, 5, $10912-10919$. 